\title{
Silent Joint in Dispute. Is Intraarticular Treatment of Temporomandibular Joint Questionable?
}

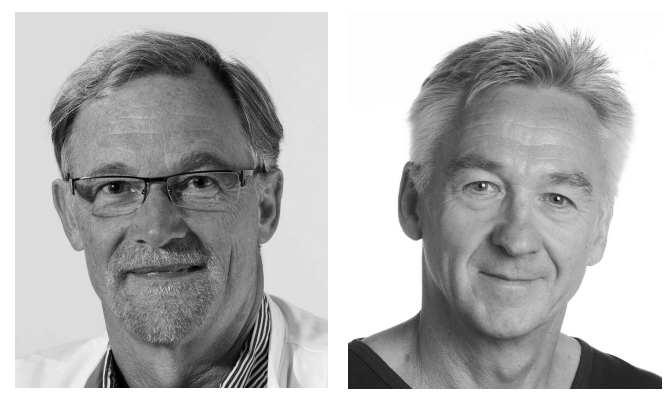

Involvement of the temporomandibular joint (TMJ) has a high prevalence in children with juvenile idiopathic arthritis $(\mathrm{JIA})^{1,2}$. Arthritis of the TMJ in the growing, young individual can have significant implications for craniomandibular growth and development ${ }^{3,4,5}$. This is because the mandibular condylar cartilage serves as the basis of the primary mandibular endochondral growth site since the growth site is placed within the intracapsular joint. Treatment aims have been to reduce TMJ inflammation and to reduce craniofacial disturbances with normalization of growth. TMJ arthritis, due to the unobtrusive character of the inflammation, has been infrequently recognized, and TMJ has been given its moniker "the forgotten joint" 6 . However, within recent years no other single joint has received as much attention in patients with JIA as the TMJ.

Locally administered therapy, typically in the form of intraarticular corticosteroids (IACS) in the TMJ, has been a frequent strategy in the management of children with JIA within the last 10 years $7,8,9,10,11,12$. In general, studies have reported on symptomatic relief after IACS injection in the TMJ, including reduced pain and changes in the physical examination findings of maximal incisal opening ${ }^{7,8,12}$. Two of these studies reported magnetic resonance imaging (MRI) changes with improved effusion in $67 \%{ }^{8}$ and reduced inflammation in the TMJ in $39 \%^{12}$ after IACS. The use of IACS in TMJ has been performed in the light of recognizing IACS as a safe, efficient local treatment of inflammation in synovial joints ${ }^{13}$, but evidence for the safety and efficacy in the TMJ has not been provided. In the systematic review of Stoustrup, et $a l^{14}$ on the efficacy and safety of IACS for TMJ arthritis in JIA, several limitations of these studies were identified, including retrospective design, lack of a control group, lack of patient/outcome assessor blinding, and lack of standardized clinical and radiological followup measures. Further limitations were a small number of patients included in the studies, no information on concurrent use of systemic medical treatment that might have an effect on TMJ inflammation, and a short period of followup ${ }^{14}$. From the review it was concluded that high-quality studies with prespecified research protocols, standardized treatment and followup procedures, and uniform clinical inclusion criteria to reduce bias were imperative. Further, what seems to be forgotten regarding the TMJ is its unique nature concerning embryology, anatomy, and role of condylar growth, and maturation in the growth and development of the mandible. Mandibular development is strongly dependent on the lengthening of the condyle provided by bone formation, which is in turn dependent on endochondral ossification of the secondary cartilage forming part of the condylar growth zone directly facing the inferior joint space. Different cartilage exists for articulation and growth in synovial joints while the TMJ presents the growth site in relation to the articulating cartilage, implicating a direct influence of inflammation in the growth process ${ }^{15}$ and a possible adverse effect for local medical agents such as corticosteroids.

In this issue of The Journal, Lochbühler, et al $^{16}$ focus on the use of IACS for the treatment of arthritis in the TMJ of patients with JIA. The Swiss group assessed the immediate and longterm effect of IACS for TMJ arthritis on inflammation and growth disturbances. They found that despite decreasing the inflammatory activity, as seen on MRI, no prevention of osseous condylar deformations and improvement of the ramus growth were observed. They performed an MRI of the TMJ for 33 consecutive children, and during the same sedation they injected corticosteroid in the TMJ if active inflammation of the joint was observed on MRI. The indication of corticosteroid injection in the TMJ was an inclusion criterion for the study. It is remarkable that the age of the patient group was relatively young, averaging under 6 years, making it possible to evaluate the effect of the corticosteroid injection on growth changes of the craniomandibular complex.

See MRI effects of TMJ steroid injection, page 1514

Personal non-commercial use only. The Journal of Rheumatology Copyright @ 2015 . All rights reserved. 
Repeated MRI were done at 2 intervals, averaging between 2 and 4 months, and later after 6 to 12 months. IACS was repeated if TMJ arthritis had not improved. Out of a total of 66, 19 of the TMJ were injected once, 45 repeatedly, and 2 were never injected. The cumulative injected corticosteroid dose varied considerably from 6 to $72 \mathrm{mg}$ per joint. Lochbühler and colleagues compared 2 groups of patients who either had a successful intraarticular injection or had the corticosteroid placed extraarticularly based on the amount of fluid visible within the joint space. Quite a large number of injections were located extraarticularly (42\%). Although, presumably, the effect of intraarticularly located corticosteroid would be more effective in reducing inflammatory synovitis than extraarticularly located corticosteroid, it cannot be excluded that, even extraarticularly, corticosteroid administered just outside the joint capsule would have an effect on the TMJ arthritis. Because of the nature of the treatment design it seems difficult to perform a double-blind study. It could, however, be essential to perform a placebo-controlled trial comparing the effect of intraarticular saline with the effect of IACS.

In the subgroup with IACS a negative mean growth rate of the mandibular ramus was observed compared to a positive growth rate in the subgroup with extraarticular corticosteroid. This means that despite the alleviation of inflammation, the risk for longterm growth changes worsened with IACS. These findings are in line with the results obtained for experimental TMJ arthritis in young rabbits showing that IACS was accompanied by a significant reduction in mandibular growth compared with controls with untreated TMJ arthritis ${ }^{17,18}$. In JIA, the primary concern over TMJ arthritis on a longterm basis is disturbances in craniofacial growth and TMJ function. Although the findings in experimental arthritis could not be directly applied to humans, the results showed an urgent need to address these concerns in future human studies. The immediate symptomatic relief after IACS in TMJ arthritis described in several studies was hitherto observed for only a short period, and growth changes were not recorded in the past as described in the article by Lochbühler ${ }^{16}$. Another interesting finding was that $26 \%$ of the TMJ had progressed to severe osseous deformity, including $21 \%$ with intraarticular calcifications, which was associated with a high cumulative dose index ${ }^{16}$. Calcification in the TMJ in relation to IACS has been reported to cause ankylosis ${ }^{19,20}$. Ankylosis of the TMJ is a condition leading to severe eating difficulties and malnutrition, pain, dysfunction, and a possible joint replacement.

The Stoustrup, et al systematic review called for general guidelines for the indications and use of IACS in children and adolescents with $\mathrm{TMJ}^{14}$. Such guidelines should be based on well-designed studies before general conclusions on the efficacy and safety of IACS therapy are made. With the article by Lochbühler, et al $^{16}$, the understanding of the consequences of IACS for TMJ arthritis has been advanced and should encourage future research to focus on the craniofacial growth disturbances on a longterm basis when managing TMJ arthritis.

The study from the Swiss group is remarkable for several reasons. For the first time it has attempted not only to look at the immediate clinical effect of IACS for TMJ arthritis, but also to look at the longterm consequences of the steroid injection using repeated MRI of the TMJ to assess the inflammatory changes as well as the mandibular growth changes over time. As a result of their study it can be speculated whether it is meaningful to administer a treatment of the TMJ giving temporary relief of symptoms while increasing the risk of growth and functional impairment.

TROELS HERLIN, MD, Professor,

Department of Pediatrics,

Aarhus University Hospital

THOMAS KLIT PEDERSEN, DDS $\mathrm{PhD}$, Professor,

Department of Maxillofacial Surgery,

Aarhus University Hospital,

Section of Orthodontics,

Aarhus University,

Aarhus, Denmark.

Address correspondence to Prof. Herlin, Department of Pediatrics, Aarhus University Hospital, Palle Juul-Jensens Boulevard 99, Aarhus N, Denmark.E-mail: troeherl@rm.dk

\section{REFERENCES}

1. Kuseler A, Pedersen TK, Herlin T, Gelineck J. Contrast enhanced magnetic resonance imaging as a method to diagnose early inflammatory changes in the temporomandibular joint in children with juvenile idiopathic arthritis. J Rheumatol 1998;25:1406-12.

2. Weiss PF, Arabshahi B, Johnson A, Bilaniuk LK, Zarnow D, Cahill AM, et al. High prevalence of temporomandibular joint arthritis at disease onset in children with juvenile idiopathic arthritis, as detected by magnetic resonance imaging but not by ultrasound. Arthritis Rheum 2008;58:1189-96.

3. Stabrun AE, Larheim TA, Höyeraal HM, Rösler M. Reduced mandibular dimensions and asymmetry in juvenile rheumatoid arthritis. Pathogenetic factors. Arthritis Rheum 1988;31:602-11.

4. Pedersen TK, Jensen JJ, Melsen B, Herlin T. Resorption of the temporomandibular condylar bone according to subtypes of juvenile chronic arthritis. J Rheumatol 2001;28:2109-15.

5. Arvidsson LZ, Flatø B, Larheim TA. Radiographic TMJ abnormalities in patients with juvenile idiopathic arthritis followed for 27 years. Oral Surg Oral Med Oral Pathol Oral Radiol Endod 2009;108:114-23.

6. Arabshahi B, Cron RQ. Temporomandibular joint arthritis in juvenile idiopathic arthritis: the forgotten joint. Curr Opin Rheumatol 2006;18:490-5

7. Ringold S, Torgerson TR, Egbert MA, Wallace CA. Intraarticular corticosteroid injections of the temporomandibular joint in juvenile idiopathic arthritis. J Rheumatol 2008;35:1157-64.

8. Arabshahi B, Dewitt EM, Cahill AM, Kaye RD, Baskin KM, Towbin RB et al. Utility of corticosteroid injection for temporomandibular arthritis in children with juvenile idiopathic arthritis. Arthritis Rheum 2005;52:3563-9.

9. Fritz J, Thomas C, Tzaribachev N, Horger MS, Claussen CD, Lewin JS, et al. MRI-guided injection procedures of the temporomandibular joints in children and adults: technique,

Personal non-commercial use only. The Journal of Rheumatology Copyright $\subset$ $\subset$ 2015. All rights reserved 
accuracy, and safety. Am J Roentgenol 2009;193:1148-54.

10. Parra DA, Chan M, Krishnamurthy G, Spiegel L, Amaral JG, Temple MJ, et al. Use and accuracy of US guidance for image-guided injections of the temporomandibular joints in children with arthritis. Pediatr Radiol 2010;40:1498-504.

11. Habibi S, Ellis J, Strike K, Ramanan AV. Safety and efficacy of US-guided CS injection into temporomandibular joints in children with active JIA. Rheumatology 2012;51:874-7.

12. Stoll ML, Good J, Sharpe T, Beukelman T, Young D, Waite PD, et al. Intra-articular corticosteroid injections to the temporomandibular joints are safe and appear to be effective therapy in children with juvenile idiopathic arthritis. J Oral Maxillofac Surg 2012;70:1802-7.

13. Padeh S, Passwell JH. Intraarticular corticosteroid injections in the management of children with chronic arthritis. Arthritis Rheum 1998;41:1210-4.

14. Stoustrup P, Kristensen KD, Verna C, Küseler A, Pedersen TK, Herlin T. Intra-articular steroid injection for temporomandibular joints arthritis in juvenile idiopathic arthritis: a systematic review on efficacy and safety. Semin Arthritis Rheum 2013;43:63-70.

15. Peltomäki T, Kreiborg S, Pedersen TK, Ogaard B. Craniofacial growth and dento-alveolar development in juvenile idiopathic arthritis patients. Semin Orthod 2015;21:84-93.
16. Lochbühler N, Saurenmann R, Müller L, Kellenberger C. MRI assessment of TMJ involvement and mandibular growth following corticosteroid injection in juvenile idiopathic arthritis. J Rheumatol 2015;42:1514-22.

17. Stoustrup P, Kristensen KD, Küseler A, Gelineck J, Cattaneo PM, Pedersen TK, et al. Reduced mandibular growth in experimental arthritis in the temporomandibular joint treated with intra-articular corticosteroid. Eur J Orthod 2008;30:111-9.

18. Stoustrup P, Kristensen KD, Küseler A, Gelineck J, Cattaneo PM, Pedersen TK, et al. Condylar lesions in relation to mandibular growth in untreated and intra-articular corticosteroid-treated experimental temporomandibular joint arthritis. Clin Exp Rheumatol 2010;28:576-83.

19. Aggarwal S, Kumar A. A cortisone-wrecked and bony ankylosed temporomandibular joint. Plast Reconstr Surg 1989;83:1084-5.

20. Schindler C, Paessler L, Eckelt U, Kirch W. Severe temporomandibular dysfunction and joint destruction after intra-articular injection of triamcinolone. J Oral Pathol Med 2005;34:184-6.

J Rheumatol 2015;42:1361-3; doi:10.3899/jrheum.150653 